\title{
Guarding Against Threatening HIV Prevention Messages: An Information-Processing Model
}

\author{
Stephen J. Blumberg, PhD
}

\begin{abstract}
Previous research has suggested that fear-provoking HIV prevention messages can lead to defensive coping strategies among sexually active students who encounter such messages. An information-processing model of defensive responses is proposed that identifies and operationally defines four mediating processes-attention avoidance, blunting, suppression, and counterargumentation - that may lead to the rejection or denial of threatening health messages. Attention avoidance occurs when people indiscriminately avoid all messages; blunting is the use of distraction to avoid only threatening information in the message. Suppression occurs when people try to stop thinking about the information and avoid forming inferences about its self-relevance; counterargumentation is the biased assessment that follows comprehension and arises along with self-relevant elaboration. Situational influences on people's choice of defensive coping strategy are considered, and implications for researchers and practitioners are discussed.
\end{abstract}

One of the persistent problems in AIDS education and prevention is the tendency for people to believe that "it won't happen to me." To change people's views about their vulnerability to HIV and AIDS, many educators have returned to the standard foundation of preventive medical education: fear. Instilling fear ("it can happen to you") has long been assumed to motivate people to engage in self-protective behaviors that will combat any unwanted disease. ${ }^{1,2}$ Yet, increasing fear and anxiety can have unintended consequences. The self-protective behaviors that are stimulated by fear may be fashioned to reduce directly the anxiety itself rather than the risk of contracting the disease. When this happens, increasing the use of fear within a message may not lead to behavior change but rather to defensive and maladaptive coping responses. Identifying the nature of these undesired responses is the primary goal of this article.

Stephen J. Blumberg is a senior survey statistician at the Centers for Disease Control and Prevention, National Center for Health Statistics, Hyattsville, Maryland.

Address reprint requests to Stephen J. Blumberg, $\mathrm{PhD}$, Centers for Disease Control and Prevention, National Center for Health Statistics, 6525 Belcrest Road, Room 850, Hyattsville, MD 20782; phone: (301) 458-4107; fax: (301) 458-4035; e-mail: SBlumberg@cdc.gov.

This project was completed in partial fulfillment of the requirements for the doctoral degree at the University of Texas at Austin. I am grateful for the invaluable assistance and thoughtful comments of Bob Helmreich, Bob Josephs, Anne Seraphine, Bobbie Spellman, and especially Bill Swann. Appreciation is also expressed to two anonymous reviewers.

Health Education \& Behavior, Vol. 27 (6): 780-795 (December 2000)

(C) 2000 by SOPHE

780 


\section{THE CONSEQUENCES OF FEAR APPEALS}

The hypothesis that increasing fear leads to defensive responses is supported by systematic research. Early studies of fear appeals, for example, demonstrated that moderate levels of arousal increase attitude and behavior change, but excessive arousal does not. ${ }^{3}$ Janis suggested that from low to moderate levels of arousal, increases in fear arousal lead one to become more mindful of the health-related recommendations made in the message. However, he suggested that increases from moderate to high levels of fear arousal lead to efforts to find weaknesses in the message's position or maladaptive methods of reducing the fear. ${ }^{4}$

Some later research, however, failed to support Janis's conclusion. That is, in some studies, highly arousing messages led to greater attitude change than less-arousing messages. ${ }^{5}$ Leventhal explained this apparent contradiction by suggesting that when the threat can be easily eliminated by maintaining one's current behavior, increases in fear arousal are more likely to lead to danger control processes that "solve" the problem. ${ }^{6}$ On the other hand, when changes in behaviors cannot completely eliminate the threat, people are more likely to engage in fear control processes that reduce the threat but do not solve the problem. Thus, the perceived level of self-efficacy determines whether increases in fear lead to increased attitude and behavior change or to increased use of defensive processes that reduce the immediate experience of anxiety. ${ }^{7}$

\section{HIV PREVENTION, FEAR APPEALS, AND DENIAL}

The aim of these defensive responses is better understood than the nature of the responses themselves. Studying the nature of these defensive reactions requires the presence of a real or fabricated threat. As such, today's HIV risk reduction and prevention programs can provide a suitable and widely accepted paradigm for this research. Within these widespread programs, students often learn several threatening facts about HIV infection and AIDS: (a) AIDS currently has no cure, (b) AIDS leads to almost certain death, and (c) HIV infection is a very stigmatizing condition. ${ }^{8}$ When these medical and social messages are combined with discussions or videotapes that reinforce the idea that the student could be at risk for contracting the disease, intense anxiety should develop. These programs then hope that the anxiety will be a motivating force that leads the student to engage in safer sexual behaviors. ${ }^{9}$

Regrettably for AIDS educators, the arousal that results from these prevention programs may also motivate the student to implement defensive responses that reduce his or her anxiety. Anxiety and defensive responses may be more likely for students who have experienced sexual intercourse (hereafter, sexually active students) because sexual activity is the primary mode of transmission of the disease. Defensive responses may also be more likely for sexually active students because they should perceive less self-efficacy for preventive behaviors than students who have never experienced sexual intercourse (hereafter, abstainers); after all, sexual assertiveness, safer sex negotiation, and condom use are more difficult than maintaining abstinence.

In two studies based on these assumptions, Morris and Swann demonstrated that following either of two fear-inducing HIV prevention films, ${ }^{10,11}$ sexually active college students (but not abstainers) reported reduced perceptions of risk for HIV infection, reduced 
interest in additional information about AIDS, reduced desire to be a peer AIDS educator, and reduced memory for AIDS-relevant information from the film. ${ }^{12}$ These researchers concluded that

as we "turn up the volume" on our persuasive communications, it may be possible to turn up the volume too high - that is, that overly powerful messages may produce denial and therefore have an effect opposite to that intended on the people who are most at risk. (p. 70, emphasis added $)^{12}$

In making this conclusion, Morris and Swann endorsed a view that denial "is the avoidance of anything that may be perceived as threatening. This may involve distancing oneself from any information that is relevant to the perceived threat or suppressing knowledge about the threat" (p. 60). ${ }^{12}$ Such a broad flexible definition of denial is limited because it prevents AIDS educators from predicting precisely what effects their programs might have.

Morris and Swann's results are unlikely to be the direct result of a single coping mechanism. For example, if sexually active students developed counterarguments against the film's message, they may have created feelings of invulnerability and reports of reduced risk for HIV infection. Similarly, if students were trying to control and suppress their fear-provoking thoughts about AIDS, it may not be surprising that they would avoid additional information about AIDS. The memory deficits for information in the film, on the other hand, may result if students engaged in self-distraction and blunted the impact of the message by reducing the attention paid to portions of the film. These three means for coping with fear-provoking persuasive communications (listed here as counterargumentation, suppression, and blunting, respectively) represent conceptually distinct constructs. I propose that these three defensive coping responses differ principally in the level of information processing prior to the defense.

\section{AN INFORMATION-PROCESSING MODEL OF DEFENSIVE RESPONSES}

Most theories on the processing of persuasive communications have been generated by consumer psychologists and have developed out of Krugman's observation that effective advertising is moderated by the personal involvement of the audience. Krugman even foreshadowed current cognitive psychological accounts of memory and cognitive elaboration when defining involvement as "the number of conscious 'bridging experiences,' connections, or personal references per minute that the viewer makes between his own life and the stimulus" (p. 355). ${ }^{13}$ In this tradition, Greenwald and Leavitt developed an information-processing framework consisting of four distinct levels, each of which is characterized by increasing degrees of audience involvement. ${ }^{14,15}$

The first level is preattention, during which the subconscious remains attentive to the presence of novel or unfamiliar stimuli. When the preattentive mind detects an affectively significant unfamiliar stimulus or a special stimulus such as one's own name, it instigates a conscious orienting response toward the stimulus. At this focal attention level, the conscious mind then begins to form categories (such as words or objects) from the message's sensory content and accesses the meanings of these words. Next, at the comprehension level, the words in the message are analyzed together, and propositional representations (or sentence meanings) are formed. Finally, these representations may be integrated with 
the message recipient's already existing conceptual and self-relevant knowledge to generate inferences at the elaboration and assessment level. At this level, the inferences can be used to counterargue against the message; if seemingly valid counterarguments can be made, a dismissal of the truth value of the message may result.

Like all modular mental systems, this framework proposes that information passes from one stage to another and is modified in different ways at each stage. ${ }^{16}$ At each level of this model, the representation of the message becomes more abstract, and therefore the degree of effort and involvement necessarily increases as message processing moves from one level to another. However, following each stage, the information may be prematurely output. ${ }^{17}$ That is, processing of the information may cease, and the product may take one of many possible early exits. Why would the process stop midstream? Most mental systems, including this proposed message-processing framework, require additional resources to modify the information at each higher level. Therefore, a person who is unwilling or unable to allocate these necessary resources should fail to fully process the message.

An inherent assumption, of course, is that people may be motivated to withhold effort and resources during the processing of the message and therefore may be able to choose the exit appropriate for that information. For example, a person may choose to ignore a persuasive television commercial, to listen to (but not carefully evaluate) a chemistry lecture, and to elaborate and carefully assess a persuasive speech from Bill Clinton. Why are many messages ignored, some just comprehended, and perhaps fewer elaborated and assessed? A better understanding of why people will choose different degrees of involvement with a message and a better understanding of the consequences of an early exit when processing threatening persuasive communications, may improve the operationalization and understanding of avoidant coping strategies.

\section{COPING STYLES WITHIN THIS INFORMATION-PROCESSING MODEL}

The message-processing framework just described provides four possible exits during the processing of persuasive communication. These exits, which can also be construed as coping styles, follow each of the four levels of this framework (see Figure 1), and I will now consider each of them in turn. Because consciously choosing each exit can be construed as an avoidance of further processing, I have adopted Greenwald's strategy ${ }^{14}$ for labeling these exits: avoidance of attention, avoidance of comprehension, avoidance of inference, and complete assessment.

\section{Avoidance of Attention}

A message that is ejected after the preattentive level is one that has not elicited an orienting response. This may occur if the person is distracted or asleep, if the message is not affectively significant itself, or if the message has been repeated enough times to lead to habituation. ${ }^{15}$ Each of these causes of avoidance of attention, however, occurs when an individual does not have conscious control over his or her orienting response. Conscious avoidance of attention is likely to occur when people are concentrating their focus and attention on other more important stimuli. For example, a person who is concentrating on one person's voice at a cocktail party is ignoring other voices that are also present. ${ }^{18} \mathrm{By}$ avoiding attention to the other voices, this person may avoid hearing unpleasant news but 


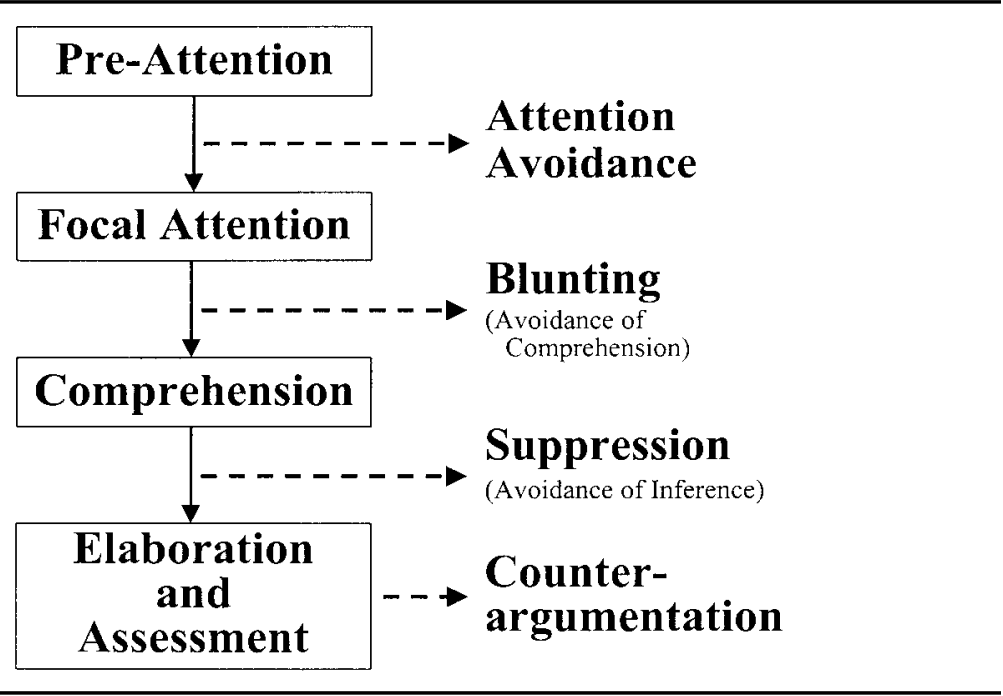

Figure 1. An information-processing model of defensive responses.

will also indiscriminately avoid hearing news that may be of significant interest. As such, unless a person could foresee that all stimuli are threatening stimuli, it is unlikely that he or she would choose to defend himself or herself against threatening messages by avoiding the processing of messages altogether.

\section{Avoidance of Comprehension}

Once an individual has oriented toward the message, he or she will begin to recognize that pictures, objects, or words are present in the message and will access the stored meanings of those words. Because the words in the message have been processed, they may cue the perceiver to stop processing the message. Greenwald suggested that this process occurs frequently with television commercials. Because of an intrinsic lack of interest in these commercials, "hearing or seeing a brand name may act as a cue to avoid comprehension of the message in which it occurs" (p. 123). ${ }^{14}$

Similarly, hearing or seeing a word that evokes a sense of anxiety may lead a person to avoid comprehension of the threatening message in which the word occurs. These emotional responses can occur prior to any further inferential processing of the context within which the word exists. ${ }^{19}$ As such, any word that evokes negative affect (e.g., AIDS) may provide a cue that signals the perceiver to avoid further processing. This signal may then instigate defensive processes that encourage distraction.

The use of distraction as a style for coping with threatening messages is an important part of theories on cognitive informational coping styles. ${ }^{20,21}$ In these conceptions of attentional styles, people differ in their desire to seek out and process threat-relevant cues in a situation. People who readily encode these cues in threat conditions are called monitors; people who choose to avoid information or distract themselves are called blunters. Research on the behavior of blunters indicates that they prefer to avoid threat-relevant information in medical settings, such as before gynecologic surgery, ${ }^{22}$ colposcopy, ${ }^{23}$ or dental treatment. ${ }^{24}$ By comparison, monitors desire more information not only about the 
procedures but also about the causes of their illnesses. ${ }^{25}$ By avoiding this threatening information through distraction, blunters are able to reduce their anxiety relative to monitors in these settings ${ }^{26}$ In fact, blunters are so adept at reducing arousal that blunters who watched the horror film Nightmare on Elm Street showed little increase in electrodermal arousal during the film. ${ }^{27}$

What exactly is being attended to by monitors and avoided by blunters is still unclear. ${ }^{28}$ Nevertheless, engaging in this distraction is certainly a form of mental disengagement and suggests that a better operationalization of one type of avoidant coping may be avoidance of comprehension, or blunting. People choosing this form of avoidant coping should demonstrate increased distraction during a threatening message and/or decreased comprehension of that message.

Indeed, Blumberg demonstrated that sexually active college students with high scores on the blunting subscale of the Monitoring/Blunting Style Scale ${ }^{29}$ had reduced memory for AIDS-relevant information presented in a threatening HIV prevention film. ${ }^{30}$ This reduction, however, was not accompanied by a significant reduction in focal attention toward the film, as recorded by a hidden video camera focused on the position of the experimental participants' eyes. How could blunters appear to pay attention to the film but still have memory deficits indicating inattention? Recent work by Boden and Baumeister suggests one possibility. ${ }^{31}$ In their studies, people with a repressive coping style (who are characterized by a desire to avoid negative affect) were able to generate their own "happy thoughts" and recall happy memories while they watched a particularly unpleasant movie. Recalling one's own happy memories enabled repressors to avoid comprehension of the message without the need for external distractions. Perhaps blunters (who are characterized by a desire to avoid threatening information) can also be choose cognitive rather than behavioral strategies to distract themselves. Avoidance of comprehension may be aided by external distracting stimuli but does not require such stimuli.

\section{Avoidance of Inference}

In contrast to blunters, monitors prefer more information and therefore should more readily comprehend the information they do receive. How could these people defend themselves against the anxiety caused by this self-relevant threatening information?

Greenwald suggested that comprehension of the sentences that make up a threatening communication does not lead to an awareness that the message is self-relevant. ${ }^{14}$ Recognizing the self-relevant nature of the message requires elaboration and inferences (the fourth level). Thus, if one were to avoid drawing inferences, one would avoid the anxiety associated with the threatening conclusion. For example, understanding the sentence, "Unprotected sexual intercourse can put one at risk for contracting HIV," does not require one to draw inferences such as, "I have engaged in unprotected sexual intercourse and therefore I might be at risk." Information concerning a threat can be obtained without inferring its relevance.

Nevertheless, it is unlikely that the meaning of this sentence can remain cognitively activated without risking the possibility that a self-relevant inference will "accidentally" be drawn. One means of avoiding the possibility of this unwanted inference would be to remove the meaning (or main idea) of the sentence from conscious activation as soon as possible. Yet, the conscious suppression of a thought is easier said than done. ${ }^{32}$

When one attempts to remove a thought from consciousness, the person activates an automatic monitoring process that searches for signs of the to-be-suppressed thought in consciousness. ${ }^{32}$ If this monitoring process finds one, then it signals an operating process 
to work harder to suppress the thought. In this way, the monitoring process acts like a lookout - making sure that the unwanted thought remains in hiding and notifying the operating process if the thought is detected. Ironically, however, this monitoring process keeps the unwanted thought active at a deep cognitive level. ${ }^{33}$ In fact, research on the cognitive accessibility of this thought suggests that deeply activated thoughts are even more accessible than surface-activated thoughts. ${ }^{34}$ For example, compared to people who are trying to think about a house, people who are trying not to think about a house respond more slowly to the name of the ink color that the word house is written in during a Stroop interference task,,$^{35}$ and they are more likely to respond with the word house when prompted by the word home in a speeded word association task. Like primed thoughts, these intentionally suppressed thoughts become deeply activated and highly accessible to consciousness.

Because suppressing thoughts keeps these thoughts active at some level, suppression may not be an effective long-term strategy for dealing with threatening information. Suppression of emotion-laden thoughts may even intensify the emotional content of those thoughts. ${ }^{36}$ Nevertheless, avoidance of inference, or thought suppression, is likely to be used by unsuspecting individuals in response to the anxiety produced by threatening messages and therefore supression can be considered a form of mental disengagement. People choosing this form of avoidant coping should show evidence of increased accessibility on tasks such as speeded word association, ${ }^{34}$ sentence fragment completion, ${ }^{37}$ lexical decision making, ${ }^{38}$ and Stroop color-naming interference tasks. ${ }^{34}$

In one test of this operationalization of suppression, sexually active students and abstainers were shown a threatening HIV prevention film and then were asked to identify the colors of words presented on a computer screen.$^{39}$ Using a Stroop color word interference paradigm under conditions of cognitive load, Blumberg and his colleagues successfully demonstrated that the word AIDS led to increased interference for sexually active students who saw an HIV prevention film compared to abstainers who saw the film and sexually active students who did not see a film. Assuming that sexually active students would experience greater anxiety as a result of the film, the highly accessible nature of the word AIDS suggests that suppression of the message was used to control the anxiety produced by HIV prevention messages.

\section{Complete Assessment}

Elaboration and assessment of any message requires the message recipient to weigh the facts and inferences present in the message with any other relevant information easily accessible in memory. The ease with which this information may be remembered is determined in part by the resources devoted to the task and in part by the search strategy employed. Both can be influenced by differences in motivation and personal goals, and therefore these differences can go a long way toward determining if the message will be certified or rejected. In particular, threatening messages can lead to increased motivation to protect oneself by rejecting the message.

Festinger and Maccoby were the first to hypothesize about the development of counterarguments to aid in the rejection of unfavorable persuasive communications. ${ }^{40}$ According to their hypothesis, recipients of a threatening message are not passive but rather are actively generating arguments that contradict the threat. These subvocalized arguments may oppose the threatening message directly, endorse the recipient's own original opinion, or derogate the threatening messenger's competence or character. Because these arguments enable the recipient to resist the impact of the message, it is not 
surprising that greater numbers of counterarguments are generated when the advocated position is more threatening. ${ }^{41}$ This motivation to generate counterarguments may also be moderated by beliefs about whether one is capable of discovering and performing an effective response that will overcome the threat. ${ }^{42}$

As part of drawing inferences about the self-relevant nature of threatening messages, people are likely to make judgments about whether they have the skills or resources to overcome or manage the threat in this situation. If the demands of the situation or the threat itself suggest that one's ability to manage the threat is low, then the person may be especially motivated to find ways to counterargue against the message. ${ }^{7}$ This motivation may lead one to generate more counterarguments or endorse more readily the truth value of these possibly weak (or wholly untrue) counterarguments. In doing so, the person may come to reject the message itself. For example, if a person feels that abstinence or condom use is not a realistic option for protecting himself or herself against the spread of HIV, then he or she may be more easily persuaded by self-generated counterarguments that suggest that HIV infection is only a threat to "other" populations or that his or her risk behaviors are not strongly linked to infection. Perceived uncertainties in the scientific knowledge about HIV transmission rates, risk factors, and availability of a cure can only serve to increase the chance that counterarguments will be successful.

Use of motivated counterargumentation may also lead one to focus on certain arguments and ignore others. For example, when estimating their own vulnerability to a health threat, people may be motivated to focus on their own preventive behaviors and ignore their own risk factors. This selective focus would likely result in perceptions of reduced vulnerability. ${ }^{43}$ Efforts to reduce this unrealistic optimism by leading participants to believe others engage in fewer risk behaviors have been largely unsuccessful, in part because participants' counterarguments then lead them to believe either that they engage in risky behaviors even less often or that their risk behaviors are less related to health problems and are less personally important to avoid. ${ }^{44}$ Both counterarguments do not occur at once; participants who reduced their perceptions of their behavior frequencies were less likely to change their evaluation of the risk behaviors. As might be expected, one counterargument is as good as any other, provided that it refutes the threat present in the message.

\section{What About Denial?}

By its very nature, motivated counterargumentation can lead to a denial of the threat itself. Traditionally, the concept of denial has been difficult to operationalize. Psychoanalytic theorists have considered denial to be a primitive unconscious defense mechanism that reduces negative affect by repudiating aspects of reality. ${ }^{45}$ In endorsing this view, Dorpat considers denial to consist of screening behaviors that follow immediately after a preconscious appraisal of the danger. ${ }^{46}$ As a result of this screening behavior, unpleasant thoughts are replaced with less painful ones. According to Dorpat, this process occurs before the associated affect is even experienced. Within the message-processing framework presented so far, this screening behavior would not be considered denial; rather, this behavior would be better classified as avoidance of attention or comprehension.

Instead, within this framework, denial is better conceptualized as a cognitive mechanism that requires thinking and cognitive resources to perform counterargumentation. This conceptualization is suggested by the nature of people's denial responses. Often, people's explanations for why they fail to believe a threatening message indicate that they have processed the good evidence within that message. For example, after listening to 
mock interviews of students and learning the students' serostatus, undergraduates perceived their own personalities and behaviors as more similar to HIV-negative students than to an HIV-positive students, even though the interviews heard were identical. ${ }^{47}$ This "similarity bias" only occurred, however, on behaviors and traits that are HIV relevant (e.g., impulsive, promiscuous). These results suggest that before engaging in this self-protective social comparison behavior, participants in the study had already processed information that suggested which behaviors and traits were HIV relevant.

For denial to be effective, it must directly address the threat-relevant information in the message, and therefore this information must first be propositionally represented and elaborated on. In a sense, this conceptualization of denial is similar to the less advanced stages of denial detailed by Breznitz in his seven stages of denial. ${ }^{48}$ According to Breznitz, a recognition of the existence of threatening information is followed by the least degree of reality distortion (i.e., denial) necessary to protect oneself from the anxiety or pain. Denial of personal relevance and denial of urgency provide arguments against the self-relevant and temporal-relevant nature of the threat. For example, knowing about the interests, hobbies, and goals of one's current sexual partner may lead one to argue erroneously that this partner has never been at high risk for HIV infection, which in turn may lead one to minimize the threat of AIDS by believing it is not currently a relevant danger to one's self. ${ }^{49}$ Denial of vulnerability and denial of responsibility provide arguments that influence one's sense of self-efficacy and helplessness. For example, knowing the sexual history of one's partner may lead one to argue perhaps incorrectly that condoms are unnecessary, which in turn may lead to feelings of invulnerability. ${ }^{50} \mathrm{On}$ the other hand, promiscuous gay men may be aware that they are in a high-risk category, but this knowledge may lead them to abdicate responsibility for protection; they may think that contracting HIV is inevitable or that their "low-risk" partners should be responsible for protecting themselves. ${ }^{51}$ In any case, for one to employ any of the four kinds of denial presented here, one must be aware that "knowing your partner" and using condoms are protective behaviors or that male homosexuals with numerous sexual partners may be at particular risk for contracting HIV. At each of these stages, an understanding of the message is necessary before the message can be rejected, and therefore each of these stages can fit comfortably within the conceptualization of denial as motivated counterargumentation.

Considering denial as a process of counterargumentation that occurs subsequent to the elaboration of the message allows for denial to be measured in an experimentally meaningful way. This initial elaboration should produce heightened arousal as the threat is perceived. Indeed, experimental participants who prefer denial as an avoidant coping strategy do show greater autonomic arousal after receiving threatening information and prior to defensive cognitive reconstruction. ${ }^{52}$ In addition, people who are engaging in counterargumentation should demonstrate increased comprehension of the message and increased generation of inferences from the message. However, these increases in arousal and elaboration are necessary but not sufficient for measuring counterargumentation because people who fully endorse the veracity of the message will also demonstrate these increases. People who are engaging in counterargumentation must also have readily accessible arguments that refute parts of the message or bolster their own original opinions and attitudes. Perceptions of reduced vulnerability to HIV, increased confidence that protective actions have been sufficiently taken in the past, and decreased perceptions of the relevance of the message to oneself can provide evidence that recipients are bolstering their own original opinions by focusing on preventive behaviors and ignoring risk factors. 


\section{SITUATIONAL INFLUENCES ON THE USE OF DEFENSIVE RESPONSES}

When a message is threatening, especially when self-efficacy is low, individuals may implement certain maladaptive coping strategies-identified here as attention avoidance, blunting, suppression, and counterargumentation. The choice of which coping strategy to use may be based on personal preferences that can be assessed with personality measures such as the Monitoring/Blunting Style Scale,${ }^{29}$ the White Bear Suppression Inventory, ${ }^{53}$ and the Need for Cognition Scale. ${ }^{54}$ Yet, improving the persuasive impact of threatening messages is unlikely to be as simple as creating messages that obstruct people's preferred defensive responses. In fact, people are likely to consider both their personal preferences and the anticipated threatening situation when choosing an appropriate strategy.

Identifying which situational contexts will lead to which coping strategy has been difficult. In one such attempt, Breznitz suggested that a more intense threat will lead to greater distortion of reality and more advanced stages of denial. ${ }^{48}$ Within the context of the information-processing model presented here, anticipating exceptionally potent dangers within a message should lead to a greater use of attention avoidance and/or blunting strategies. For instance, a person who anticipates that a scary movie will create lasting nightmares is more likely to walk out of the theater early than is a person who predicts the movie will just lead to an increased heart rate. Though intuitively sound, this hypothesis has been difficult to test empirically due to ethical restrictions on the presentation of highly threatening messages.

Other attempts to identify situational determinants of defensive strategies have proposed that people engage in a cost-benefit analysis of the use of defensive responses ${ }^{55} \mathrm{In}$ this conception, defensive responses provide certain benefits at certain costs, and aspects of the message as well as aspects of the situation in which the message is presented may influence the calculation of costs and benefits. For example, walking out of the scary movie has the benefit of eliminating nightmares but may lead to more interpersonal costs if attending this movie with a new dating partner than if attending it alone. Thus, one should be more likely to choose blunting in the latter situation than in the former. Similarly, Breznitz suggested that less advanced stages of reality distortion (such as counterargumentation) should be chosen more often when defending against ambiguous messages than when defending against unambiguous messages because the difficulties (i.e., costs) of developing counterarguments against the former are fewer than against the latter. ${ }^{48}$

Benefit calculations can also be influenced by the situation. When a person is not capable of coping with a stressor in a functional and adaptive manner (such as when the individual is too weak to act or when the threat is uncontrollable), short-term defensive responses may be beneficial until the individual gains strength or control. ${ }^{56}$ For example, immediately after receiving news about the death of a loved one, blunting or suppressing the news may allow the bereaved to gather the strength needed to eventually handle the loss. Therefore, blunting and suppressing should be chosen more often immediately after receiving this news than in the days or weeks following the news. According to this cost-benefit conception, recognizing the increased benefit of engaging in short-term defensive responses should lead people to choose these responses when the situation limits the resources available for adaptive coping.

Additional costs and benefits of engaging in various defensive responses may be suggested by self-presentation concerns. As mentioned earlier, within certain situations, 
ignoring a message may be socially unacceptable, which increases the costs of blunting a threatening message. Similarly, being familiar with the arguments present in a message may provide benefits that outweigh the costs of exposing oneself to the message. When people know that their responses to a persuasive message will be available for public scrutiny or when their responses can lead to social approval, self-presentation concerns should lead them to pay more attention to the message. ${ }^{57}$

In one experiment testing this hypothesis, sexually active college students categorized as high or low blunters based on their blunting scores ${ }^{29}$ were led to believe that they were either going to discuss the content of an HIV prevention film with another student or tested on their memory for the AIDS-relevant information presented in the film. ${ }^{58}$ Participants were encouraged to pay greater attention to the message so that the discussion would go smoothly or so that the experimenter would not be disappointed by their lack of recall for the message. As expected, these manipulations eliminated the effect of participants' blunting style; high blunters and low blunters did not differ in their memory for AIDS-relevant information from the film.

However, these manipulations did not lead to overall increases or decreases in perceptions of risk or intentions to use condoms. Just because the costs of blunting had been increased, the motivation to defend against the message had not been removed. Instead, increasing the costs of blunting merely increased the number of counterarguments developed. ${ }^{58}$ When the context in which a persuasive communication occurs provides people with goals that contrast with their preferred defensive responses, people are capable of employing coping styles other than those predicted by individual differences. Health educators should note, therefore, that changes in the situation that encourage increased involvement with the message will not necessarily thwart all defensive strategies and lead to increased persuasion.

\section{SUMMARY AND IMPLICATIONS}

Increasing self-perceptions of vulnerability and fear is a central component in most theories of health behavior change (e.g., the Health Belief Mode ${ }^{59}$ ). The model presented here suggests several reasons why fear-based interventions may be ineffective for certain people in certain situations. To summarize, risk sensitization requires the deliberate processing of information. This processing occurs in stages (preattention, focal attention, comprehension, and elaboration/assessment), and defensive coping styles implemented at any of these stages can limit the risk sensitization that occurs. This model refines the language used to describe each of these defenses (attention avoidance, blunting, suppression, and counterargumentation) and provides conceptual definitions for each.

This model suggests how defensive coping occurs but is limited in its ability to predict who will defend and when. The interaction of situational forces and individual differences makes this prediction difficult, though the self-efficacy literature has contributed greatly toward easing this prediction. ${ }^{7}$ One conclusion that may be drawn, however, is that hindering defenses by increasing message recipients' ability or motivation to process the threatening information may improve the effectiveness of these interventions. Some techniques, such as increasing individuals' self-efficacy for changing behaviors, may act on multiple coping styles by increasing willingness to pay attention and decreasing motivation to argue against the benefits of the behavior change. Yet, most improvements to fear-based interventions will likely influence just one defensive coping style and there- 
fore must be used in tandem to prevent message recipients from simply switching from one defensive coping strategy to another.

Suggestions for reducing blunting were included in the section on situational influences. For example, blunting can be reduced if people believe they will be tested on their memory for the information or required to discuss the information at a later time. Blunting may also be reduced by bolstering people's expectations concerning their ability to cope with the anticipated threat. These expectations can be easily manipulated by simply changing the title of the message: people pay more attention to positively titled messages (e.g., the benefits of condom use) than to negatively titled messages (e.g., the costs of not using condoms), especially when the message itself is framed negatively (as most threatening HIV prevention messages are).$^{60}$ Alternatively, these expectations about coping ability can also be enhanced by increasing the positivity of people's moods or self-relevant thoughts prior to the threatening message. ${ }^{61}$ In experimental studies, participants were more receptive to negative and potentially threatening self-relevant information after they recalled positive events from their past,$^{62}$ wrote about a personally important value ${ }^{63}$ experienced success on an ostensibly difficult anagram task ${ }^{64}$ or received positive personality evaluations from an ostensibly reliable source. ${ }^{65}$ Any of these experimental manipulations could be included as preliminary exercises in HIV risk reduction programs.

Suppression should be reduced when the target audience engages in personal assessments of their own risk. The link between risk knowledge and personal behavior must be made actively by the audience and not simply provided in the message. One reportedly effective technique that can be used in HIV risk reduction programs creates a personal risk continuum. ${ }^{66}$ In this activity, intervention participants worked as a group to develop a list of various sexual acts and then place these behaviors along a continuum representing levels of risk for HIV infection (e.g., hugging and kissing were placed under no risk, oral sex without protection was placed under somewhat risky, and intercourse without a condom was placed under very risky). Each participant then used the same continuum to indicate how frequently he or she had engaged in each sexual act. Because each behavior was already linked with a risk level, participants could recognize how often their behaviors placed them on the risky end of the continuum. Such activities require participants to reflect actively on their own personal risk, which should reduce suppression.

Counterargumentation is perhaps the most flexible defensive coping mechanism and thus the most difficult to reduce. Reducing these arguments requires prevention activities tailored to the individual and his or her culture. This customization is especially difficult for media interventions. For example, messages directed toward gay men may not be as effective with non-gay-identified men who have sex with men, ${ }^{67}$ because non-gayidentified men who have sex with men may argue that others (i.e., gay men) are at higher risk. The effectiveness of counterargumentation will most efficiently be reduced in an individualized or small group setting, where intervention participants can voice their arguments and have these "myths" dismissed by a health educator.

HIV prevention videotapes can be used to trigger discussions that encourage participants to consider the relationship of the video to their own situation and the strategies that could be used to reduce their risk. In addition, discussion facilitators can correct misinformation introduced by the participants, encourage discussion of barriers to condom use, and recommend solutions individualized to the expressed concerns of the participants. Facilitators should listen for counterarguments and ask questions that may elicit counterarguments (e.g., asking participants to describe the personalities of HIV-positive individ- 
uals may reveal that participants are trying to distance themselves from these individuals; further examples are provided by Fallon ${ }^{68}$ ). Compared to videotapes alone, implementing discussions following these videotapes has been shown to increase risk perception, condom use self-efficacy, and condom acquisition ${ }^{69}$ - perhaps by limiting the effectiveness of counterargumentation.

In conclusion, when people are motivated to defend against a threatening message, the best intervention may be an interesting, attention-capturing, and culturally sensitive intervention in which participants initially feel good about themselves, later sensitize themselves to their own risk, and then have their myths dispelled by an effective health educator. Despite the intuitive nature of this recommendation, these components are missing from some interventions. For example, an evaluation of publicly funded HIV testing sites found that posttest counseling often consisted of just a 10-minute lecture on potential risks and an admonition to change one's behavior. ${ }^{70}$ This lecture should be no better than a threatening film and should result in similar defensive coping mechanisms. The model presented here provides an information-processing perspective on the reasons these components may be such important additions to HIV risk reduction interventions.

Of course, further empirical tests will be necessary to evaluate and test the model, including its application to particular threatening health messages and to various solutions for reducing defensive processing. In carrying out these tests, researchers should note that the most common outcome measures for interventions (i.e., knowledge, attitudes, and behavior change) may identify if defensive coping occurred but will rarely identify how the defensive coping occurred. For understanding how, measures of the extent to which information has been processed will be needed. Some of these measures were discussed earlier (e.g., focal attention, speeded word association, sentence fragment completion, autonomic arousal, argument accessibility); creative cognitive scientists will undoubtedly think of others. Identifying the stage in which processing has been disrupted may prove useful when attempting to improve the efficacy of a threatening message, and therefore researchers are encouraged to use these measures in their laboratories when testing the impact of a particular message.

\section{References}

1. Brandt AM: No Magic Bullet: A Social History of Venereal Disease in the United States Since 1880. New York, Oxford University Press, 1985.

2. Kleinschmidt HE: Educational prophylaxis of venereal diseases. Soc Hyg 5:27-39, 1936.

3. Janis IL, Feshbach S: Effects of fear arousing communications. J Abnorm Soc Psychol 48:78-92, 1953.

4. Janis IL: Effects of fear arousal on attitude change: Recent developments in theory and experimental research, in: Berkowitz L (ed.), Advances in Experimental Social Psychology. Vol. 3. New York, Academic Press, 1967, pp. 167-225.

5. Insko CA, Arkoff A, Insko VM: Effects of high and low fear-arousing communications upon opinions toward smoking. J Exp Soc Psychol 1:256-266, 1965.

6. Leventhal H: Findings and theory in the study of fear communications, in: Berkowitz L (ed.): Advances in Experimental Social Psychology. Vol. 5. New York, Academic Press, 1970, pp. 119-186.

7. Witte K: Putting the fear back into fear appeals: The extended parallel process model. Commun Monogr 59:329-349, 1992.

8. Gilmore N, Somerville MA: Stigmatization, scapegoating, and discrimination in sexually transmitted diseases: Overcoming "them" and "us." Soc Sci Med 39:1339-1358, 1994. 
9. Fisher JD, Fisher WA, Misovich SJ, Kimble DL, Malloy TE: Changing AIDS risk behavior: Effects of an intervention emphasizing AIDS risk reduction information, motivation, and behavioral skills in a college student population. Health Psychol 15:114-123, 1996.

10. Sunburst Communications, Marks DJ: Just Like Us: AIDS Prevention [videotape]. (Available from AIDS Risk Reduction Project, University of Connecticut, 406 Babbidge Rd., Storrs, CT 06269-1020), 1993.

11. Evers S: Not Me: Innocence in the Age of AIDS [videotape]. (Available from Pyramid Film and Video, 2801 Colorado Ave., Santa Monica, CA 90404), 1993.

12. Morris KA, Swann WB Jr: Denial and the AIDS crisis: On wishing away the threat of AIDS, in: Oskamp S, Thompson SC (eds.), Understanding and Preventing HIV Risk Behavior. Thousand Oaks, CA, Sage, 1996, pp. 57-79.

13. Krugman HE: The impact of television advertising: Learning without involvement. Public Opinion Quarterly 29:349-356, 1965.

14. Greenwald AG: Self-knowledge and self-deception, in: Lockard JS, Paulhus DL (eds.), SelfDeception: An Adaptive Mechanism? Englewood Cliffs, NJ, Prentice Hall, 1988, pp. 113-131.

15. Greenwald AG, Leavitt C: Audience involvement in advertising: Four levels. J Consumer Res 11:581-592, 1984.

16. Gilbert DT: How mental systems believe. Am Psychol 46:107-119, 1991.

17. Norman DA, Bobrow DG: On data-limited and resource-limited processes. Cognitive Psychol 7:44-64, 1975.

18. Moray N: Attention in dichotic listening: Affective cues and the influence of instructions. $Q J$ Exp Psychol 11:56-60, 1959.

19. Zajonc RB: Feeling and thinking: Preferences need no inferences. Am Psychol 35:151-175, 1980.

20. Miller SM: Predictability and human stress: Towards a clarification of evidence and theory, in: Berkowitz L (ed.), Advances in Experimental Social Psychology. Vol. 14. New York, Academic Press, 1981, pp. 203-256.

21. Miller SM: To see or not to see: Cognitive informational styles in the coping process, in: Rosenbaum M (ed.), Learned Resourcefulness: On Coping Skills, Self-Regulation, and Adaptive Behavior. New York, Springer, 1990, pp. 95-126.

22. Steptoe A, O'Sullivan J: Monitoring and coping styles in women prior to surgery. Br J Clin Psychol 25:143-144, 1986.

23. Miller SM, Mangan CE: The interacting effects of information and coping style in adapting to gynecologic stress: Should the doctor tell all? J Pers Soc Psychol 45:223-236, 1983.

24. Muris P, Jongh A de, Zuuren FJ van, ter Horst G: Coping style, anxiety, cognitions, and cognitive control of dental phobia. Pers Individ Diff 17:143-145, 1994.

25. Miller SM, Brody DS, Summerton J: Styles of coping with threat: Implications for health. J Pers Soc Psychol 54:142-148, 1988.

26. Phipps S, Zinn AB: Psychological response to amniocentesis: II. Effects of coping style. Am J Med Genetics 25:143-148, 1986.

27. Sparks GG, Spirek MM: Individual differences in coping with stressful mass media: An activation-arousal view. Hum Commun Res 15:191-216, 1988.

28. Miller SM: Monitoring and blunting of threatening information: Cognitive interference and facilitation in the coping process, in: Sarason IG, Pierce GR, Sarason BR (eds.), Cognitive Interference: Theories, Methods, and Findings. Mahwah, NJ, Lawrence Erlbaum, 1996, pp. 175-190.

29. Miller SM: Monitoring and blunting: Validation of a questionnaire to assess styles of information seeking under threat. J Pers Soc Psychol 52:345-353, 1987.

30. Blumberg SJ: The Blunting Coping Style and Threatening AIDS-Prevention Films. Poster presented at the Annual Convention of the American Psychological Society, Washington, DC, May 1998.

31. Boden JM, Baumeister RF: Repressive coping: Using pleasant thoughts and memories. J Pers Soc Psychol 73:45-62, 1997.

32. Wegner DM: Ironic processes of mental control. Psychol Rev 101:34-52, 1994. 
33. Wegner DM, Smart L: Deep cognitive activation: A new approach to the unconscious. J Consult Clin Psychol 65:984-995, 1997.

34. Wegner DM, Erber R: The hyperaccessibility of suppressed thoughts. J Pers Soc Psychol 63:903-912, 1992.

35. Stroop JR: Studies of interference in serial verbal reactions. J Exp Psychol 18:643-662, 1935.

36. Wegner DM, Gold DB: Fanning old flames: Emotional and cognitive effects of suppressing thoughts of a past relationship. J Pers Soc Psychol 68:782-792, 1995.

37. Wegner DM, Erber R, Bowman R, Shelton N: On Trying Not to Be Sexist. Unpublished manuscript, Charlottesville, University of Virginia, 1997.

38. Macrae CN, Bodenhausen GV, Milne AB, Jetten J: Out of mind but back in sight: Stereotypes on the rebound. J Pers Soc Psychol 67:808-817, 1994.

39. Blumberg SJ, Morris KA, Swann WB Jr: Thought Suppression and Threatening AIDS-Prevention Messages. Poster presented at the Annual Convention of the American Psychological Society, Washington, DC, May 1997.

40. Festinger L, Maccoby N: On resistance to persuasive communications. J Abnorm Soc Psychol 68:359-366, 1964.

41. Brock TC: Communication discrepancy and intent to persuade as determinants of counterargument production. J Exp Soc Psychol 3:296-309, 1967.

42. Wulfert E, Wan CK: Condom use: A self-efficacy model. Health Psychol 12:346-353, 1993.

43. Weinstein ND: Why it won't happen to me: Perceptions of risk factors and susceptibility. Health Psychol 3:431-457, 1984.

44. Klein WM: Maintaining self-serving social comparisons: Attenuating the perceived significance of risk-increasing behaviors. J Soc Clin Psychol 15:120-142, 1996.

45. Vaillant GE: The historical origins and future potential of Sigmund Freud's concept of the mechanisms of defense. Int Rev Psychoanal 19:35-50, 1992.

46. Dorpat TL: A new look at denial and defense. Annu Psychoanal 15:23-47, 1986.

47. Gump BB, Kulik JA: The effect of a model's HIV status on self-perceptions: A self-protective similarity bias. Pers Soc Psychol Bull 21:827-833, 1995.

48. Breznitz S: The seven kinds of denial, in: Breznitz S (ed.), The Denial of Stress. New York, International Universities Press, 1983, pp. 257-280.

49. Swann WB Jr, Silvera DH, Proske CU: On "knowing your partner": Dangerous illusions in the age of AIDS? Personal Relationships 2:173-186, 1995.

50. Cochran SD, Mays VM: AIDS-related sexual behavior and disclosure: Is it safe if you ask? $N$ Engl J Med 322:774-775, 1990.

51. Odets W: In the Shadow of the Epidemic: Being HIV Negative in the Age of AIDS. Durham, NC, Duke University Press, 1995.

52. Assor A, Aronoff J, Messe LA: An experimental test of defensive processes in impression formation. J Pers Soc Psychol 50:644-650, 1986.

53. Wegner DM, Zanakos S: Chronic thought suppression. J Pers 62:615-640, 1994.

54. Cacioppo JT, Petty RE: The need for cognition. J Pers Soc Psychol 42:116-131, 1982.

55. Lazarus RS: The costs and benefits of denial, in: Breznitz S (ed.), The Denial of Stress. New York, International Universities Press, 1983, pp. 1-30.

56. Suls J, Fletcher B: The relative efficacy of avoidant and nonavoidant coping strategies: A meta-analysis. Health Psychol 4:249-288, 1985.

57. Chaiken S: Heuristic versus systematic information processing and the use of source versus message cues in persuasion. J Pers Soc Psychol 39:752-766, 1980.

58. Blumberg SJ: Blunting, Suppression, and Counterargumentation: Defensive Responses to Threatening AIDS-Prevention Films. Ph.D. dissertation, University of Texas at Austin, 1997.

59. Rosenstock M, Strecher V, Becker M: The health belief model and HIV risk behavior change, in: DiClemente R, Peterson J (eds.), Preventing AIDS: Theories, Methods, and Behavioral Interventions. New York, Plenum, 1994, pp. 5-24.

60. Smith SM, Petty RE: Message framing and persuasion: A message processing analysis. Pers Soc Psychol Bull 22:257-268, 1996. 
61. Aspinwall LG: Rethinking the role of positive affect in self-regulation. Motivation and Emotion 22:1-32, 1998.

62. Trope Y, Neter E: Reconciling competing motives in self-evaluation: The role of self-control in feedback seeking. J Pers Soc Psychol 66:646-657, 1994.

63. Sherman DA, Nelson LD, Steele CM: Do messages on health threaten the self? Increasing the acceptance of threatening health messages via self-affirmation. Pers Soc Psychol Bull, in press.

64. Trope Y, Pomerantz EM: Resolving conflicts among self-evaluative motives: Positive experiences as a resource for overcoming defensiveness. Motivation and Emotion 22:53-72, 1998.

65. Swann WB Jr, Wenzlaff RM, Tafarodi RW: Depression and the search for negative evaluations: More evidence of the role of self-verification strivings. J Abnorm Psychol 101:314-317, 1992.

66. Kalichman SC: Preventing AIDS: A Sourcebook for Behavioral Interventions. Mahwah, NJ, Lawrence Erlbaum, 1998.

67. Goldbaum G, Perdue T, Wolitski R, Rietmeijer C, Hedrich A, Wood R, Fishbein M: AIDS community demonstration projects: Differences in risk behavior and sources of AIDS information among gay, bisexual, and straight-identified men who have sex with men. AIDS and Behavior 2:13-21, 1998.

68. Fallon SJ: How to Lead Effective HIV Prevention Discussions (available from CenterOne, 2817 East Oakland Park Blvd., Suite 200, Fort Lauderdale, FL 33306), 1996.

69. O’Donnell L, Doval AS, Duran R, O'Donnell C: The effectiveness of video-based interventions in promoting condoms acquisition among STD clinic patients. Sex Trans Dis 22:97-103, 1995.

70. Doll LS, Kennedy MB: HIV counseling and testing: What it is and how well does it work? in: Schochetman G, George JR (eds.), AIDS Testing: A Comprehensive Guide to Technical, Medical, Social, Legal, and Management Issues. 2nd ed. New York, Springer-Verlag, 1994, pp. $302-$ 319. 